\title{
Editorial preface for the special issue "Catalysis for Renewable Sources: Fuel, Energy, Chemicals"
}

The Second International Conference CATALYSIS FOR RENEWABLE SOURCES: FUEL, ENERGY, CHEMICALS (CRS-2) was held on July 22-28, 2013 at the old university town Lund, situated in the southern Sweden. The First conference CRS-1 took place in St. Petersburg on 2010, and had a great response as an event which demonstrated a high interest to the highly actual and developing trends in science and technology. The First conference collected about 200 participants from 27 countries all over the world. Among the conference organizers were Missouri University of Science and Technology, USA and Petrobras, Brazil.

The selection of CRS-2 venue was based on the intensive development of biochemical technology in Scandinavia and on the opportunity to visit the power plants, as well as the objects on production and of the biological materials, the products of fine and organic synthesis from renewable raw materials in Sweden and other neighboring countries. The Lund University was the co-organizer of the conference; the members of the Chemical Technology faculty of the University actively participated in the scientific program of the CRS-2.

The conference was devoted to a discussion of the fundamental approaches to the processes of catalytic processing of plant renewable raw materials. The main objective of this discussion is the solution of the most important and especially actual problems today - the complex and deep processing of vegetable raw materials to obtain valuable chemicals and fuels. The use of the renewable resources for energy can not only reduce the growth of consumption of traditional fossil fuels, but also reduce human impacts on the environment, including carbon dioxide emissions. Much attention was paid to the discussion of the pyrolysis, gasification, and fermentation technologies for the production of biofuels. The emphasis was made on catalytic methods to address these issues.

CRS-2 conference was attended by about 100 participants from 28 countries. The conference program included seven plenary lectures, five keynote presentations, 38 oral and 30 poster presentations. The Plenary session was opened by a recognized expert in the field of chemical engineering from Sweden, Professor Jan Brandin (Linnaeus University). He presented an overview lecture on the current state of development of the new technologies for energy production from renewable raw materials, processes, deep processing of plant materials in Sweden. Traditionally, much attention was attracted by the lecture of one of Russia's leading scientists in the field of biotechnology, director of the Institute of Biochemical Physics. NM Emanuel, Professor S.D. Varfolomeev. He spoke about the current approaches to the solution of technological problems waste into energy and fuels. The lecture by Professor Tapio Salmi (Åbo Akademi University, Turku, Finland) was devoted to the application of the principles of chemical engineering for low temperature biomass conversion. Interesting results was showed by Professor Jean Carlos Serrano- 
Ruiz from Abengoa Research Company (Seville, Spain). As follows from his report, the use of catalytic technologies, especially in the production of energy from renewable resources for energy and environmental challenges, can play a key role in the development not only in bioenergy, but also in refining. The Lecture by Professor Vladislav Sadykov from Boreskov Institute of Catalysis (Novosibirsk, Russia) was devoted to the development of the structured nanocomposite catalysts for the transformation of biofuels in the syngas and hydrogen. The audience took an interest in the lectures of Professor Simoni Meneghetti from the Federal University of Alagoas, Brazil. Her report was about the oleo-chemistry focused on biofuels production. The reported materials were focused on the technologies for processing of vegetable oils, fats, biodiesel and biokerosene. The presentation contained a lot of interesting facts and drew the attention of the audience, especially considering that Brazilian scientists and specialists are among the leaders in the biofuels production. The final plenary lecture was presented by Professor Erik Heeres (University of Groningen, The Netherlands). He paid great attention to the quantitative and qualitative evaluation of the using of the effective catalysts for biochemical intensification technologies.

The key lectures were presented by Professor Christian Hulteberg (University of Lund, Sweden), Professor Mario Meneghetti (Federal University of Alagoas, Brazil), Professor Francesco Frusteri (CNRITAE "Nicola Giordano", Messina, Italy), Prof. Boris Kuznetsov (Institute of Chemistry and chemical Technology SB RAS, Krasnoyarsk, Russia), and Professor Mani Subramanian (Center of biocatalysis and Biotechnology at the University of lowa, USA).

The sessions of the oral presentations were held in a very active atmosphere, accompanied by lots of questions and discussion. They were devoted to catalytic methods of production of the valuable products from biomass; catalysis application to obtain pure synthesis gas and pure hydrogen, cogeneration of heat and electric energy in the processes of biomass gasification and combustion; the catalytic hydrocracking and transesterification of lipids for biofuels; catalytic approaches to the production of liquid fuels from biomass by pyrolysis; development of bacterial and enzymatic processes. 